\title{
O USO DA MADEIRA NAS REDUÇÕES \\ JESUÍTICO-GUARANI DO RIO GRANDE DO SUL. \\ 3 - IMAGEM DE SÃO JOSÉ ${ }^{1}$
}

\author{
JOSÉNEWTONCARDOSOMARCHIORI I ${ }^{2}$ MARIA CRISTINA SCHULZE-HOFER ${ }^{3}$
}

\section{RESUMO}

A madeira da imagem de São José, integrante do acervo do Museu das Missões, foi anatomicamente identificada como Araucaria angustifolia (Bert.) Kuntze, o popular pinheiro-do-paraná, espécie nativa no sul do Brasil, nas partes mais elevadas de Misiones (Argentina) e no leste do Paraguai.

Palavras-chave: Anatomia da madeira, Missões Jesuíticas, escultura de São José.

\section{SUMMARY}

[Wood utilization in the Jesuitic-Guarani Missions from Rio Grande do Sul state, Brazil. 3 - Anatomical identification of Saint Joseph's sculpture].

The wood of Saint Joseph's sculpture, housed at the Missions Museum (São Miguel das Missões, Rio Grande do Sul state, Brazil), was anatomically identified as Araucaria angustifolia (Bert.) Kuntze, the popular Parana-pine, native in southern Brazil and higher regions of Misiones (Argentina) and east Paraguay.

Key words: Wood Anatomy, Jesuitic Missions, Saint Joseph's sculpture.

\section{INTRODUÇÃO}

Integrante do acervo do Museu das Missões (São Miguel das Missões, RS), a imagem de São José é de autoria desconhecida e, provavelmente, do século XVIII. Feita, originalmente, em policromia, mede $192 \times 85 \times 57 \mathrm{~cm}$ e representa uma figura masculina em pé, de cabelos compridos, nariz afilado, boca entreaberta, com barba e bigode fino. De braços flexionados, carrega o Menino Jesus no lado direito, ao passo que o esquerdo tem a mão espalmada para frente. Veste túnica curta e franzida, manto com nó do lado esquerdo, meia grossa e sapato parecido com bota. Na parte posterior, uma cavidade es-

1 Recebido em 10-8-2008 e aceito para publicação em 309-2008.

2 Engenheiro Florestal, Dr., bolsista de Produtividade em Pesquisa do CNPq, Professor Titular do Departamento de Ciências Florestais, Universidade Federal de Santa Maria, CEP 97105-900, Santa Maria, RS. balduinia@mail.ufsm.br

3 Arquiteta, Dra., IPHAN - Instituto do Patrimônio Histórico e Artístico Nacional. schulze-hofer@gmx.de tende-se das costas ao final da túnica. O Menino, de cabelos curtos e pretos, apresenta-se com túnica longa e cinta, faltando as mãos, além de parte do antebraço e pés (Figura 1A).

O presente trabalho, que trata da identificação anatômica da imagem de São José, visa a contribuir para o conhecimento sobre o uso da madeira nas reduções Jesuítico-Guarani do Rio Grande do Sul.

\section{MATERIAL E MÉTODOS}

O material estudado consiste de uma amostra de madeira, retirada da parte posterior e inferior da imagem (Figura 1B,C) no ano de 2006.

A amostra foi registrada em fichário, fotografada, acondicionada em envolope com identificação e enviada ao Laboratório de Anatomia da Madeira do Instituto Nacional de Pesquisas da Madeira, em Lohbrügge, Hamburgo (Alemanha), onde foram realizados os trabalhos de microtécnica e fotomicrografia; os autores agradecem a Sra. Eda John, pela colaboração nestas tarefas. 

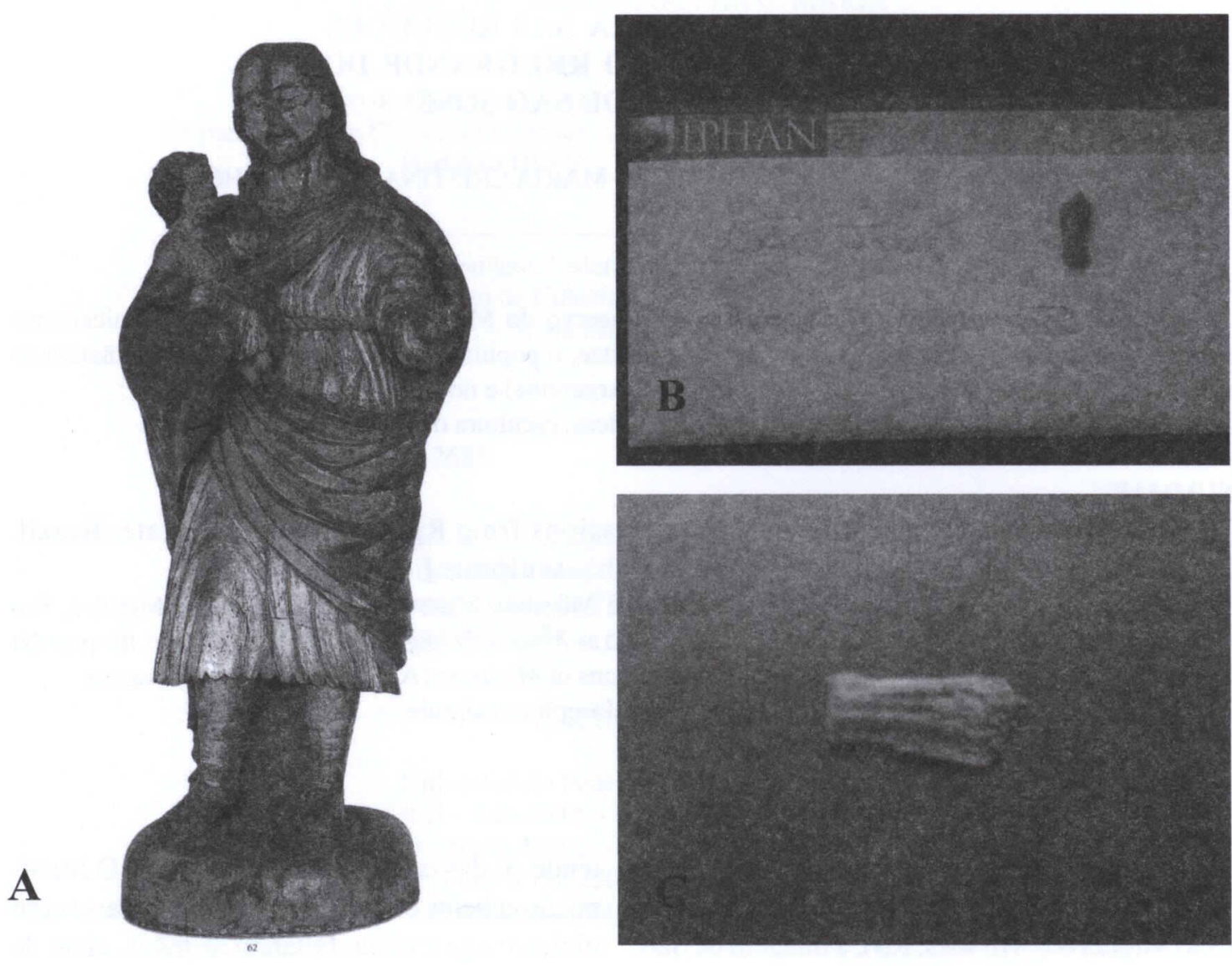

FIGURA 1 - São José. A - Imagem missioneira, conservada no Museu das Missões. B - Amostra coletada e respectivo envelope, com identificação. C - Detalhe fotográfico da amostra coletada.

Da amostra de madeira foram preparados corpos-de-prova, orientados para a obtenção de cortes anatômicos nos planos transversal, longitudinal radial e longitudinal tangencial. Os corpos-de-prova foram amolecidos por fervura em água e seccionados em micrótomo de deslizamento, modelo American Optical, regulado para a obtenção de cortes com espessura nominal de $20 \mu \mathrm{m}$. Os cortes anatômicos não sofreram coloração; no caso dos radiais, parte deles foi tratado com hipoclorito de sódio, com vistas a salientar a visualização de eventuais estruturas cristalinas nas células lenhosas. As fotomicrografias da Figura 2 foram tomadas com câmera Olympus AX, com diferentes aumentos.

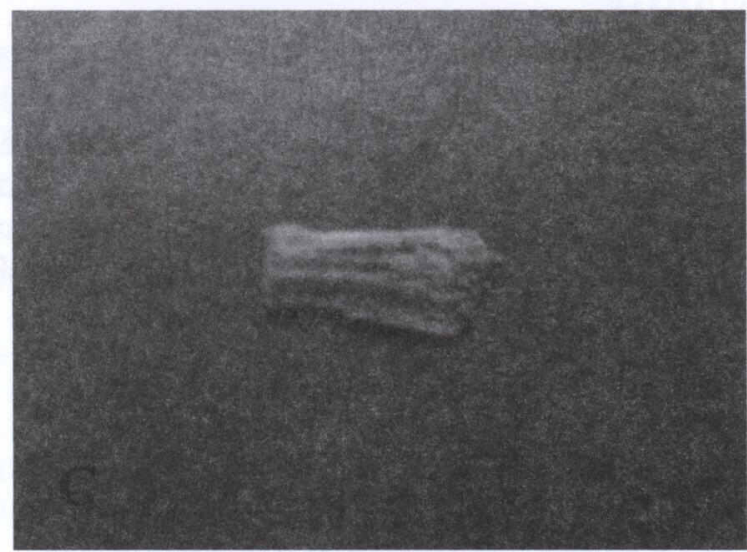

\section{DESCRIÇÃO ANATÔMICA}

Madeira de Gymnospermae ou Pinophyta, composta inteiramente de traqueídeos longitudinais e células de parênquima radial (Figura 2AF). Anéis de crescimento distintos, marcados pela transição do lenho tardio, com traqueídeos de menor diâmetro e paredes ligeiramente mais espessas, para o lenho inicial do anel seguinte, com seus traqueídeos de maior diâmetro e paredes relativamente finas (Figura 2A,B).

Traqueídeos longitudinais com pontoações hexagonais alternas, em padrão "araucarióide" (Figura 2D). Traqueídos resinosos abundantes, em plano transversal (Figura 2A, B). Espessamentos espiralados e canais resiníferos, ausentes. 

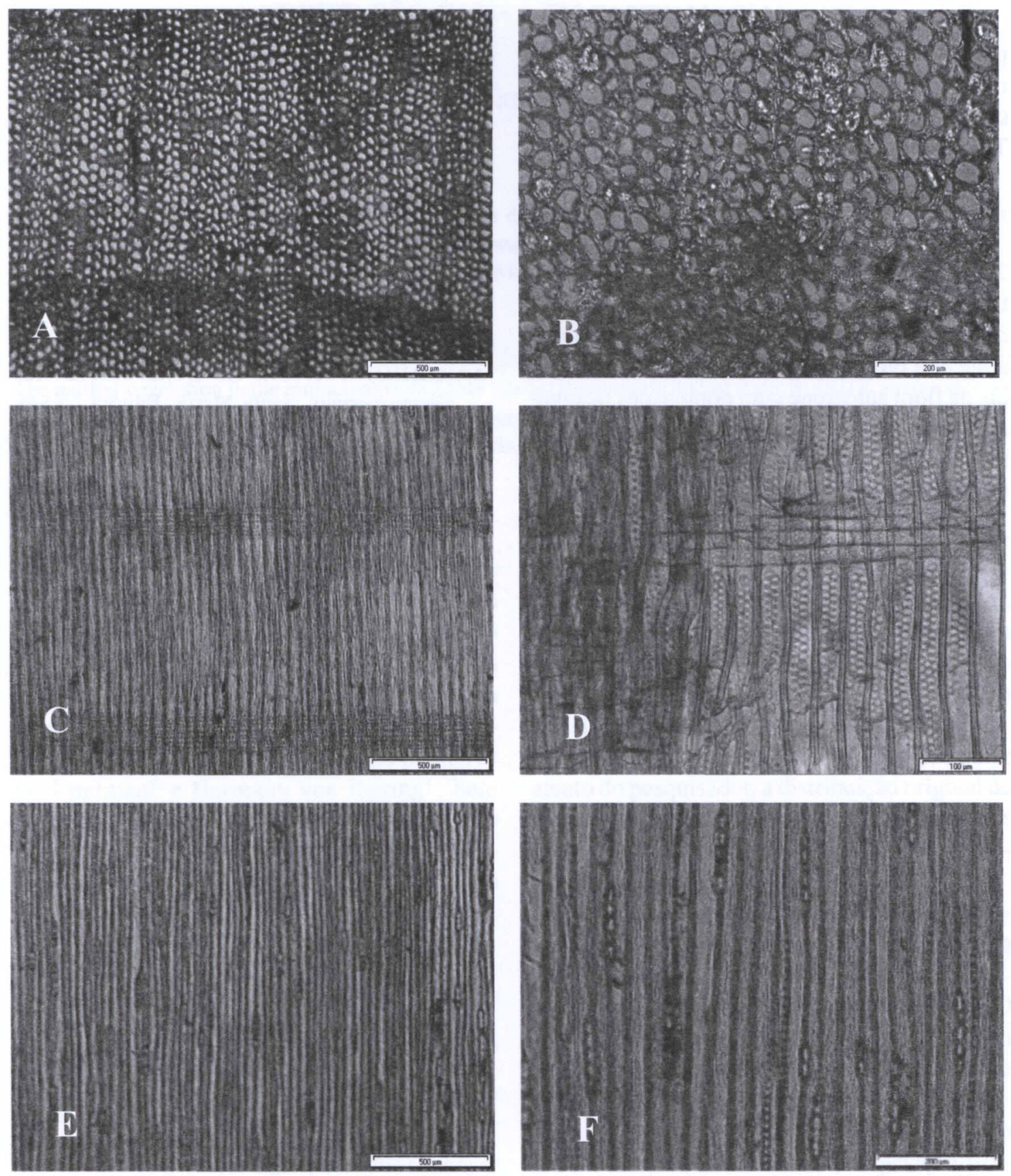

FIGURA 2 - Fotomicrografias da madeira da imagem de São José. A - Seção transversal, mostrando limite de anel de crescimento e traqueídeos longitudinais. B - Madeira composta inteiramente por traqueídeos longitudinais e células de parênquima radial, em seção transversal. C - Raios homocelulares, em seção longitudinal radial. D - Traqueídeos longitudinais com pontoações hexagonais alternas e raios compostos inteiramente por células parenquimáticas, em seção longitudinal radial. E - Raios unisseriados, em seção longitudinal tangencial. F - Raios unisseriados com 2-6 células de altura, em seção longitudinal tangencial. 
Raios homocelulares, compostos inteiramente por células de parênquima radial de paredes finas e lisas (Figura 2D). Campo de cruzamento com 3-6 pontoações cupressóides (Figura 2D). Traqueídeos radiais, ausentes.

ANÁLISE DA ESTRUTURA ANATÔMICA

Basta um rápido passar de olhos pela Figura 2D para chegar-se à identificação da madeira: trata-se, indubitavelmente, de Araucaria angustifolia (Bert.) Kuntze - a popular araucária ou pinheiro-do-paraná -, única espécie da flora autóctone com pontoações hexagonais e em arranjo alterno nos traqueídeos longitudinais (Record \& Hess, 1943; Marchiori, 1996). O gênero Araucaria, aliás, que apresenta outra espécie nos Andes austrais (Araucaria araucana), é o único com estas características em toda a flora Neotropical.

De valor diagnóstico, pode-se ressaltar, ainda, a ausência de espessamentos espiralados, de canais resiníferos e de traqueídeos radiais, bem como a não observação, no material examinado, de parênquima axial.

\section{REFERÊNCIAS BIBLIOGRÁFICAS}

MARCHIORI, J. N. C. Dendrologia das Gimnospermas. Santa Maria: Editora UFSM, $1996.158 \mathrm{p}$.

RECORD, S.J., HESS, R. W. Timbers of the New World. New Haven: Yale University Press, 1943. 640 p. 